\title{
Technical note: GODESS - a profiling mooring in the Gotland Basin
}

\author{
Ralf D. Prien and Detlef E. Schulz-Bull \\ Leibniz Institute for Baltic Sea Research, Seestraße 15, 18119 Warnemünde, Germany \\ Correspondence to: Ralf D. Prien (ralf.prien@io-warnemuende.de)
}

Received: 29 February 2016 - Published in Ocean Sci. Discuss.: 9 March 2016

Revised: 8 June 2016 - Accepted: 14 June 2016 - Published: 6 July 2016

\begin{abstract}
This note describes a profiling mooring with an interdisciplinary suite of sensors taking profiles between 180 and $30 \mathrm{~m}$ depth. It consists of an underwater winch, moored below $180 \mathrm{~m}$ depth, and a profiling instrumentation platform. In its described setup it can take about 200 profiles at preprogrammed times or intervals with one set of batteries. This allows for studies over an extended period of time (e.g. two daily profiles over a time of 3 months). The Gotland Deep Environmental Sampling Station (GODESS) in the Eastern Gotland Basin of the Baltic Sea is aimed at investigations of redoxcline dynamics. The described system can be readily adapted to other research foci by changing the profiling instrumentation platform and its payload.
\end{abstract}

\section{Introduction}

Assessing temporal dynamics in the sea of the order of hours to weeks is difficult to achieve with the classical oceanographic tools; repeated CTD casts from the ship keep the ship bound close to position for extended times, and classic moorings with instruments at several depths are limited in their vertical resolution. This problem is exacerbated in dynamic systems such as the redoxcline in the Baltic Sea with a succession of steep gradients in different properties. Profiling moorings have been used for a long time and there are commercial systems available for full ocean depth (e.g. McLane moored profiler). Most of these systems, however, use a buoyant body at the top end and a cable to the deep end as guidance for the profiling instrumentation carrier. This makes such installations vulnerable to damage, e.g. by trawled fishing nets. Here an underwater winch is used at the lower end of the mooring, and the profiling instrumentation carrier connected to the winch by a Kevlar line ascends by its own buoy- ancy through the water column before it is retracted by the underwater winch reeling the line back in.

\section{Science application}

The Gotland Basin, consisting of the Western Gotland Basin with the deepest position in the Baltic $(459 \mathrm{~m}$ at Landsort deep) and the Eastern Gotland Basin with a maximum depth of around $240 \mathrm{~m}$, is the biggest deep basin of the Baltic. The Gotland Basin is characterised by an upper layer of brackish water that is separated from the more saline waters in the deep by a strong, permanent pycnocline. This pycnocline prevents vertical mixing and with it the transport of oxygen into the waters below. Oxygen in the deeper layer is consumed by degradation of organic matter sinking from the upper water layers down through the pycnocline (e.g. Nausch et al., 2008), and consequently a gradient in dissolved oxygen concentration builds up. Oxygen is replenished mainly by major inflows of North Sea water that reach the central Baltic and replace the lower-layer waters in the deep basins (e.g. Feistel et al., 2003; Mohrholz et al., 2015). Repeated CTD casts over a period of time have shown, however, that smallscale variation of oxygen concentrations within the hypoxic down to the hypoxic-anoxic interface does occur (Jost et al., 2007) even in the stagnant periods between major Baltic inflows.

To investigate these smaller-scale dynamic signals in the redoxcline, repeated measurements are needed to assess frequency and amplitude of the small excursions of dissolved oxygen concentration and the consequences on the redox system. Repeated CTD casts from the ship cannot be carried out over the longer periods of time that would be needed to be able to build statistics and assess the dynamics under different seasonal and weather conditions. Consequently a profiling mooring was designed and built that is able to autonomously take repeated profiles at pre-programmed times 


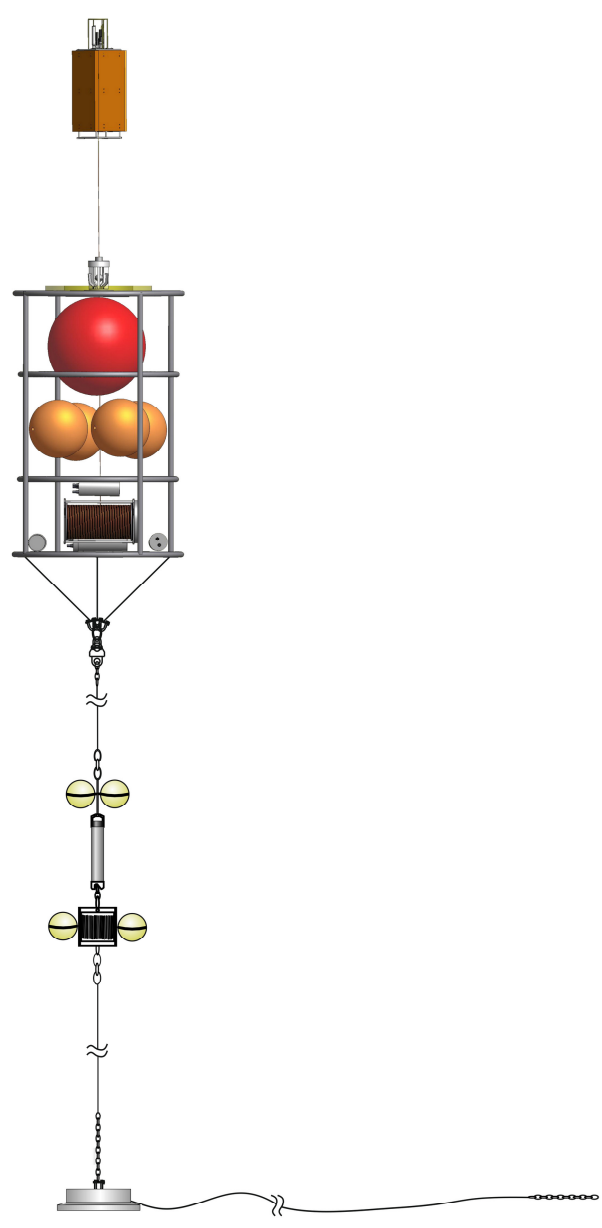

Figure 1. Sketch of the mooring with profiling instrumentation platform (PIP), underwater winch, acoustic releaser with recovery line and bottom weight with ground line (from top to bottom).

or intervals over a period of months (Prien and Schulz-Bull, 2011). The mooring was placed in close proximity to a routine monitoring station in the Gotland Deep, thus maximising the synergy from both stations; long term trends and information on important redox parameters in the standard depths at the monitoring station and smaller-scale variations from the profiling mooring nearby.

\section{Moored system}

A sketch of the profiling mooring is shown in Fig. 1. The mooring consists of the profiling instrumentation platform (PIP) that houses the instruments, the underwater winch, the recovery system and the bottom weight with ground line. This ground line serves as deployment tool and emergency recovery fallback should the acoustic releaser fail.

Care has to be taken in the choice of materials for the mooring as all components are placed in anoxic waters containing relatively high concentrations of $\mathrm{H}_{2} \mathrm{~S}$ (up to around

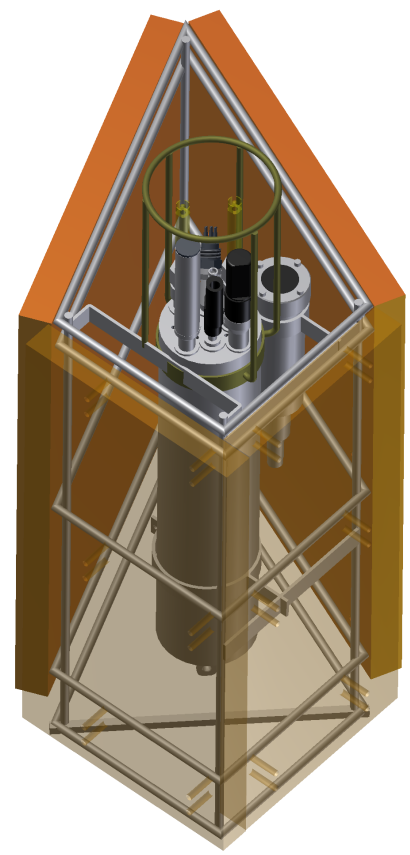

Figure 2. CAD drawing of the PIP frame with installed CTD and oxygen optode. Front sheets of syntactic foam are shown as transparent.

$80 \mu \mathrm{M}$; e.g. Nausch et al., 2008). While this can pose a corrosion problem even for high grade steels and restricts the choice of sensors on the instrumentation platform it mitigates bio-fouling issues and decreases the risk of damage by fishing operations.

\subsection{Profiling instrumentation platform}

The PIP accommodates the instrumentation payload that is shuttled through the water column. It also provides the buoyancy necessary to keep the line to the underwater winch under tension and to provide the lift for the instrument payload during the ascent through the water column. The net buoyancy of the instrumentation platform and the payload instruments determines the ascent speed as well as descent speed and power demand of the underwater winch.

A custom-built titanium frame, based on the standard design of Sea \& Sun Technology's CTD frame, with additional fixtures for the oxygen optode and syntactic foam sheets was used here for the first deployments. The standard frame from titanium rods is $550 \mathrm{~mm}$ high with a $200 \mathrm{~mm}$ square cross section. This standard design was modified by pulling out one of the corner rods of the square by another $200 \mathrm{~mm}$, resulting in a kite-shaped cross section with axes of 280 and $480 \mathrm{~mm}$. A drawing of the profiling platform is shown in Fig. 2. Six syntactic foam sheets are attached to the frame. They provide the buoyancy for the PIP as well as keeping it from rotation around the line axis as the end with the shorter buoyancy plates will always point towards the lateral current. 
The syntactic foam has a density of $300 \mathrm{~kg} \mathrm{~m}^{-3}$, resulting in a buoyancy force density of about $6870 \mathrm{~N} \mathrm{~m}^{-3}$ in water. The six sheets have a total volume of $23.25 \mathrm{~L}$ and therefore a gross buoyancy of about $160 \mathrm{~N}$. This is sufficient for the net buoyancy of about $80 \mathrm{~N}$ that is needed to keep the line tension sensor in the underwater winch from shutting off the motor (see below). The buoyancy was chosen not only to be sufficient for the line tension sensor with a small safety margin but also to minimise the buoyancy and thus the ascent speed to accommodate also slower sensors on the PIP and to minimise the power requirement on the winch for pulling the PIP back down into the parking position.

The PIP is attached to the line of the underwater winch using a stainless-steel cable bridle. This keeps the platform upright in the water column as a pre-deployment test in water showed. The shape of the platform was chosen to avoid it spinning in the case of lateral flows.

\subsection{Underwater winch}

The underwater winch is an Automatic Elevator System Type 3 from Nichiyu Giken Kogyo Co., Ltd., Japan (see Fig. 3). Its maximum deployment depth is $300 \mathrm{~m}$, and it has a length of $360 \mathrm{~m}$ of a $2.7 \mathrm{~mm}$ diameter Kevlar line. It is $1.8 \mathrm{~m}$ high with a diameter of $1 \mathrm{~m}$ and weighs $190 \mathrm{~kg}$ in air with battery packs installed. In water it is positively buoyant with a buoyancy of about $350 \mathrm{~N}$.

At preprogrammed times or intervals the underwater winch unlocks the spool of Kevlar line that is pulled out by the buoyancy of the PIP, provided that the force pulling on the line is at least $80 \mathrm{~N}$. Once the preset length is pulled out, the winch stops for a set period of time before it starts reeling the Kevlar line back in. When the hook at the end of the line is latched in the parking position, the winch control electronics is put in a wait state until the time of the next profile.

The minimum required pulling force is controlled by a line tension sensor located in the biggest of the winch's buoyancy spheres. It stops the winch paying out line when the force gets smaller than the set value. This allows profiling up to the surface in different flow regimes or tidal states as well as profiling under ice up to the ice cover. Whenever the PIP is stopped in its ascent, the tension sensor switches off the motor and thus avoids loose lengths of line that could twist or entangle. Tension control also allows deploying the mooring with the PIP connected to the winch frame using corrosion links, making the handling during deployment easier. Profiling only starts when the corrosion links are broken and the PIP exerts a force on the line by its buoyancy.

Power is supplied by Li primary battery packs, one pack $(60 \mathrm{Ah}$ at $7.2 \mathrm{~V})$ for the winch electronics and three packs of $60 \mathrm{Ah}$ at $24 \mathrm{~V}$ each for the motor. The number of profiles that can be carried out with one set of batteries depends on the depth difference for each profile; the buoyancy, size and drag coefficient of the PIP; and the flow field in the profiled water column. With the PIP described above, 220 profiles of $156 \mathrm{~m}$

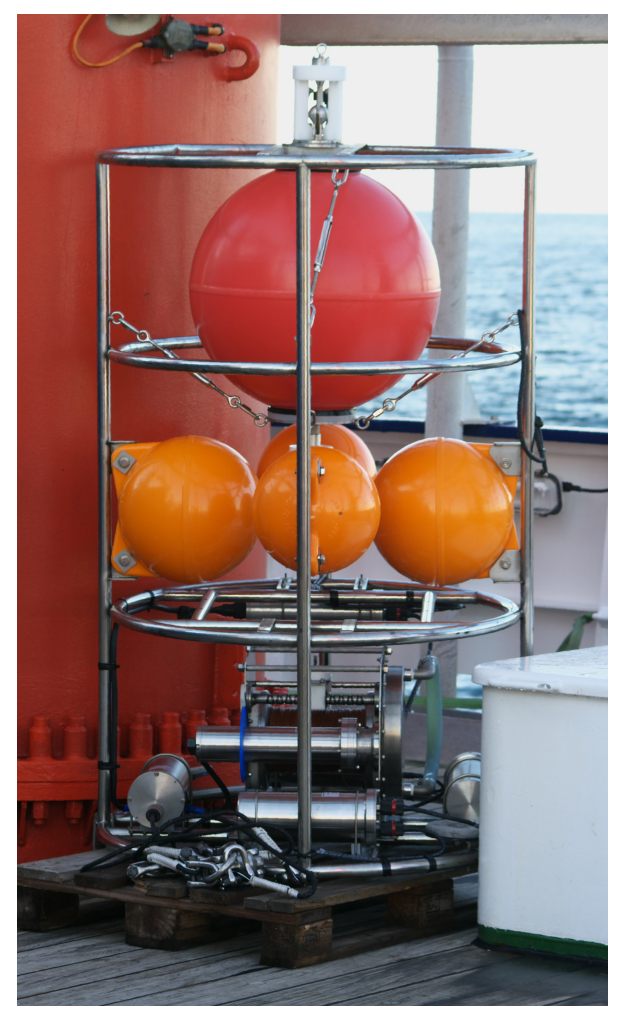

Figure 3. Underwater winch on deck after recovery from the second deployment in August 2010.

each or $34.3 \mathrm{~km}$ of profiled water column were achieved with one set of batteries. Additional battery packs can be added for increased endurance.

\subsection{Recovery system}

The recovery system for the profiling mooring consists of an acoustic releaser (KUM K/MT 572), a drum of $350 \mathrm{~m}$ $6 \mathrm{~mm}$ diameter Dynemaa recovery line (breaking strength of $27 \mathrm{kN}$ ) and buoyancy spheres. When the acoustic releaser is activated, the safety pin of the drum is pulled and the Dynemaa line is spooled off the drum as the buoyancy of the PIP, the underwater winch and the buoyancy spheres attached to the releaser pull upward. Once PIP, winch and acoustic releaser are recovered from the surface, the ground weight and ground line can be pulled up with the recovery line and all parts of the mooring are recovered.

\subsection{Instrumentation}

For the first deployments of the GODESS mooring the instrumentation payload consisted of a Sea \& Sun Technology GmbH CTD90M with additional sensors: a Seapoint Sensors Inc. turbidity sensor, a Turner Designs Inc. Cyclops-7 fluorometer, an AMT GmbH oxidation-reduction potential (ORP) sensor and an AMT GmbH pH glass electrode sensor. Additionally a fast dissolved oxygen optode Rinko (JFE 


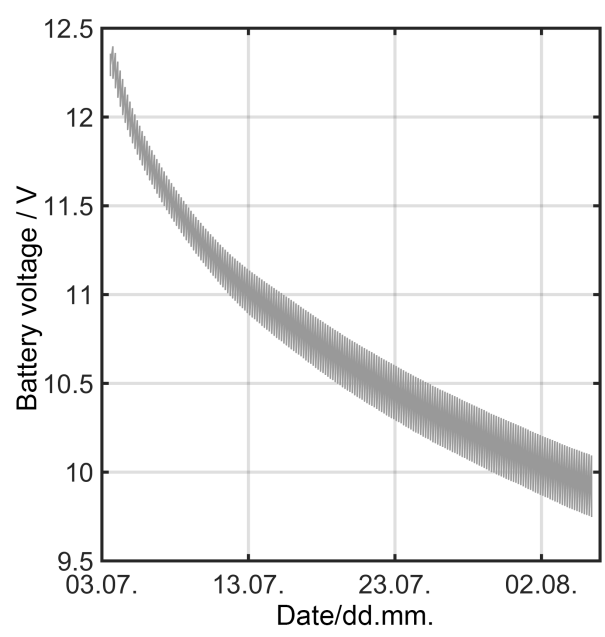

Figure 4. Battery voltage over the time of the second deployment in July/August 2010 (grey line). The voltage drops during profiling and recovers during the $4 \mathrm{~h}$ sleep period.

Advantech Co. Ltd) in a separate housing was installed on the PIP and connected to the CTD that provides the Rinko with power and logs the data.

The choice of sensors for the profiling mooring is limited by the anoxic conditions at the deep end of the profile, where the PIP is parked between profiles. The $\mathrm{H}_{2} \mathrm{~S}$ in the anoxic waters can degrade sensor performance. $\mathrm{H}_{2} \mathrm{~S}$-safe sensors can also suffer these problems as manufacturers specify $\mathrm{H}_{2} \mathrm{~S}$ resilience with the standard operation mode such as casts from a ship in mind; storing a sensor in $\mathrm{H}_{2} \mathrm{~S}$-rich waters while not operating is not an application scenario considered routinely by manufacturers.

All sensor data are logged by the CTD90M at about $4 \mathrm{~Hz}$. For those sensors that are fast enough, i.e. with a response time less than $0.25 \mathrm{~s}$, the vertical resolution during the ascent of the PIP at $0.36 \mathrm{~m} \mathrm{~s}^{-1}$ (typical for the first deployments) is about $9 \mathrm{~cm}$. The CTD's internal memory (64 megabytes) is sufficient for at least $80 \mathrm{~h}$ of logging at this rate and therefore not a limitation for the system.

Power for all sensors is provided by eight size-C alkaline batteries in the CTD. Power consumption for the whole sensor suite including the Rinko oxygen optode is $0.92 \mathrm{~W}$ during measurement. The battery power is sufficient for $44 \mathrm{~h}$ of measurement ( 220 profiles with recording intervals of $12 \mathrm{~min}$ length each); the power consumption during the intervals between profiles is negligible. The battery voltage drop during the second deployment (Fig. 4) over time suggests that a total recording time of about $50 \mathrm{~h}$ would have been possible before the supply voltage drops below $9.5 \mathrm{~V}$, still $0.5 \mathrm{~V}$ higher than the threshold for the CTD electronics to switch itself off.

The CTD and oxygen sensor were installed in the PIP side by side with the built-in sensors of the CTD and the sensing surface of the oxygen sensor pointing upwards.

\subsection{Operation}

Recording of the sensor signals in the CTD has to be synchronised with the operation of the underwater winch. As the two units have no electrical or other communications link they are synchronised by their real-time clocks (RTCs). Neither the underwater winch nor the CTD features a highprecision RTC, but the first deployments allowed determining the drift between the clocks to be in the order of $1.3 \mathrm{~s}$ per day (with the CTD clock lagging behind the winch clock). This drift, however, is likely dependent on the temperature during the deployment. As the temperature variation at $180 \mathrm{~m}$ depth is very small, it is safe to assume the same drift rates for future deployments of the same instruments. When the CTD is programmed to start 2 min ahead of the winch starting to release line, all profiles over a deployment of 3 months should be captured in full at a recording interval length that is 2 min longer than the ascent time of the PIP.

The time between profiles depends on the measurement task; in the three deployments undertaken so far it has been $1 \mathrm{~h}$ for a short $17 \mathrm{~h}$ test deployment, $4 \mathrm{~h}$ in the second deployment and $8 \mathrm{~h}$ for the third. The maximum endurance for the three deployments at 220 profiles would have been 9 days, 36 days and 73 days respectively.

\section{Results}

\subsection{First deployment}

A first test deployment at the GODESS position in the Gotland Deep was carried out in May 2010. The mooring layout was modified in that the recovery system was not installed; the end of the ground line was attached to a second ground weight with a further line with buoyancy spheres and a surface marker buoy attached. Recovery was carried out by latching on to the surface marker buoy and bringing in the line, second ground weight, ground line, winch and PIP. During the $17 \mathrm{~h}$ deployment the winch was programmed to carry out hourly profiles from about 150 to $3 \mathrm{~m}$ depth. For the first deployment the CTD was left running during the whole of the deployment; data for the ascents as well as the descents and parking phases exist. During normal deployments the CTD starts measurements shortly before the ascent commences and stops shortly after the ascent has finished to conserve energy and storage. The data of the periods between profiles gained in this first deployment show that the PIP stays at depth without much movement (the peak-to-peak variation of pressure is about $0.07 \mathrm{dbar}$ ), so it can be assumed that lateral currents were very low.

The ascent is highly reproducible in speed; only the first profiles show some deviation at the beginning, being a little slower at the start of the ascent. The ascent speed is about $0.36 \mathrm{~m} \mathrm{~s}^{-1}$ on average, starting at about $0.37 \mathrm{~m} \mathrm{~s}^{-1}$ at $150 \mathrm{~m}$ and slowing down to about $0.33 \mathrm{~m} \mathrm{~s}^{-1}$ at $3 \mathrm{~m}$. The reason 


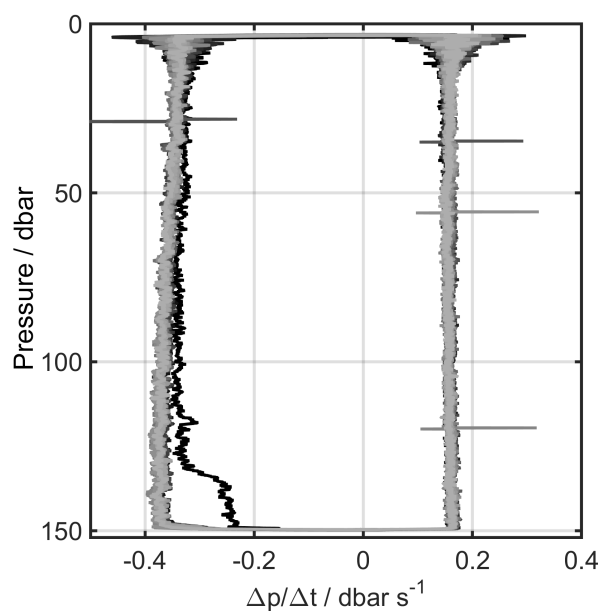

Figure 5. Ascent speed (in bar $\mathrm{s}^{-1}$ ) for the 17 profiles of the first deployment. Profiles are colour-coded, changing gradually from the first profile in black to the last one in light grey.

for the slowdown during ascent is thought to be the change of leverage on the underwater winch's drum exerted by the Kevlar line as it is spooled off by the pull of the PIP's buoyancy. At the beginning the layer of spooled line is thick (i.e. leverage high), thinning as the line is paid out. The buoyancy change of the PIP due to density changes in the surrounding water does work in the same direction, but the density change from about $1010.1 \mathrm{~kg} \mathrm{~m}^{-3}$ at $150 \mathrm{~m}$ depth to about $1005.8 \mathrm{~kg} \mathrm{~m}^{-3}$ at $3 \mathrm{~m}$ depth is too small (about $0.4 \%$ ) to explain the differences in ascent speed. On the way down the speed is fairly constant at about $0.16 \mathrm{~m} \mathrm{~s}^{-1}$. For the routine deployments the data will be taken on the upcast; for sensors with slower response times it might be advantageous to change the PIP so that the measurements are taken on the descent. Figure 5 shows the temporal differentials of measured pressure during the first deployment.

\subsection{Second deployment}

The second deployment was the first test of the complete system, i.e. including the recovery system. Figure 6 shows the main components of the profiling mooring on deck before deployment on 3 July 2010. Recovery commenced on $5 \mathrm{Au}$ gust 2010 (33 days after deployment). The system recorded 198 profiles from about $185 \mathrm{~m}$ depth to about $40 \mathrm{~m}$ depth, one profile every $4 \mathrm{~h}$. The performance during ascent was comparable to the first deployment, showing the same slowdown of the ascent at shallower depths and also the slower start of the ascent for the first few profiles. The average ascent speed was again about $0.36 \mathrm{~m} \mathrm{~s}^{-1}$.

All sensors worked well for the whole deployment; only the data from the $\mathrm{pH}$ sensor show unexpected variation in the deep that can be attributed to the sensor operation (see discussion below). The inertial period of the Gotland Basin (about $14 \mathrm{~h}$ ) can be clearly seen in most sensor signals $(t$ (see

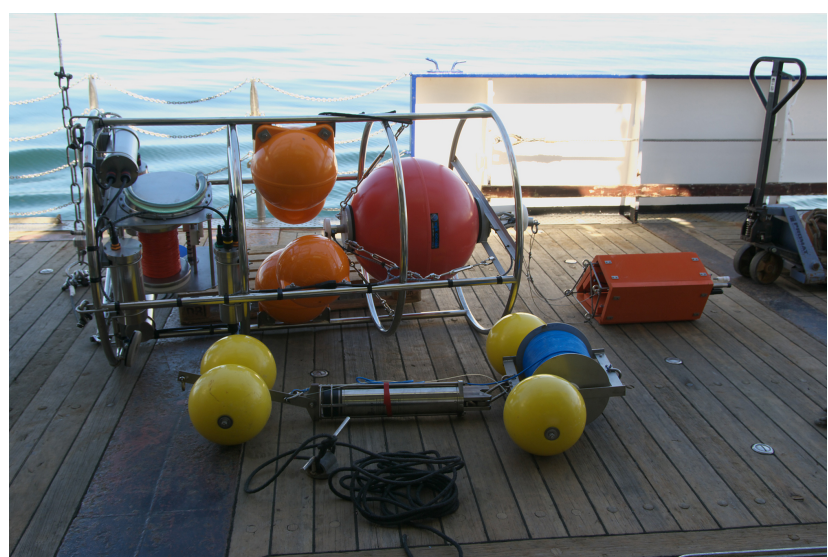

Figure 6. Mooring components laid out on deck before the second deployment in July 2010. Recovery system with acoustic releaser (front), underwater winch (back left) and profiling platform with instruments (back right).

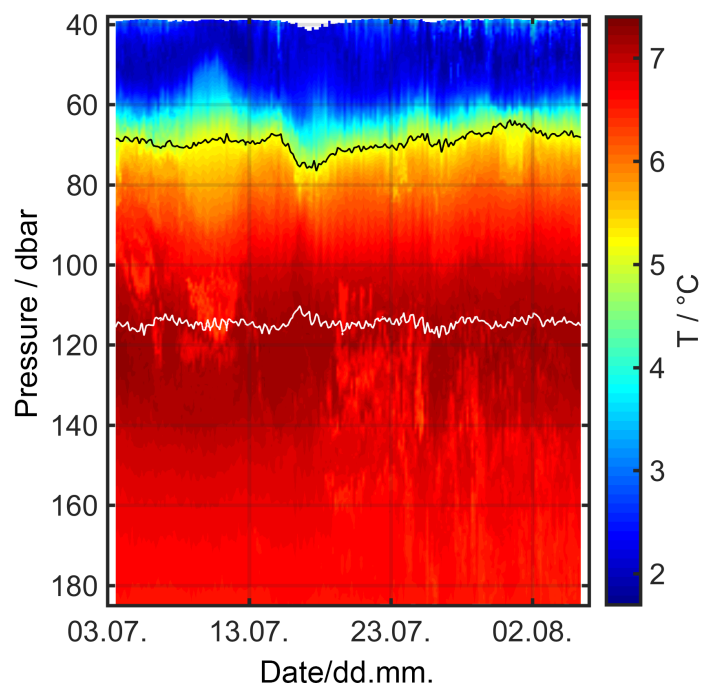

Figure 7. Plot of temperature (colour-coded) over deployment date and pressure for the second deployment, 3 July-5 August 2010. The lines at around $70 \mathrm{dbar}$ (black) and around $115 \mathrm{dbar}$ (white) denote the isopycnals of 1007.6 and $1009.5 \mathrm{~kg} \mathrm{~m}^{-3}$ respectively, indicating the division between oxic and hypoxic (upper line) and between hypoxic and anoxic waters (lower line).

Fig. 7), $S$, dissolved oxygen (see Fig. 9), ORP, turbidity). The minimum depth recorded by the CTD on the PIP does vary very little, a clear sign that the currents were low. Around 17 July 2010 the minimum depth reached by the PIP is about $2 \mathrm{~m}$ deeper than usual, and at the same time the redoxcline is shifted downwards by the same amount.

Figure 7 shows the temperature plotted colour-coded over deployment time and pressure. At the minimum depth of the PIP, around the $40 \mathrm{dbar}$ level, low temperatures of around $2.5^{\circ} \mathrm{C}$ are measured; this cool water between 40 and $60 \mathrm{dbar}$ is the winter water, which while cooled during the previ- 


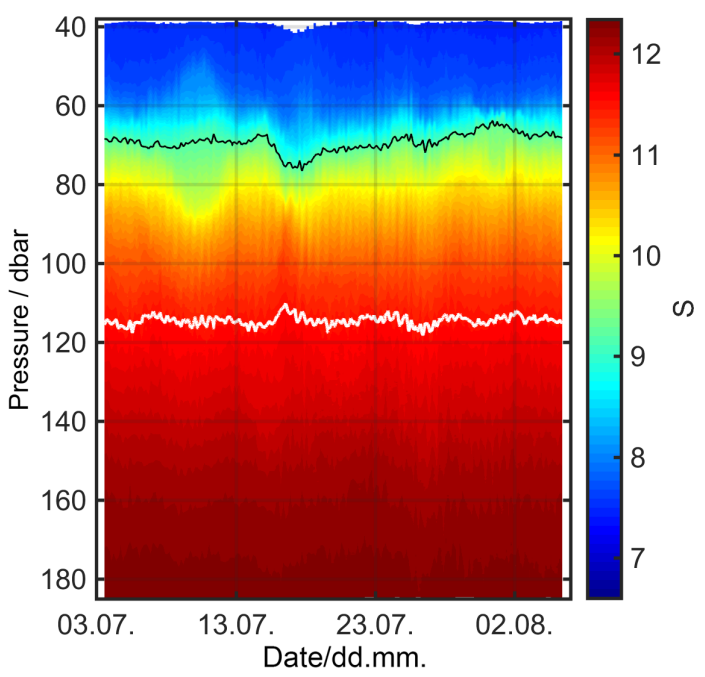

Figure 8. Plot of salinity in practical salinity units (colour-coded) over deployment date and pressure for the second deployment, 3 July-5 August 2010. The lines at around 70 dbar (black) and around 115 dbar (white) denote the isopycnals of 1007.6 and $1009.5 \mathrm{~kg} \mathrm{~m}^{-3}$ respectively, indicating the division between oxic and hypoxic (upper line) and between hypoxic and anoxic waters (lower line).

ous winter sank down to the pycnocline at around $70 \mathrm{dbar}$. The warmest water in the profiles can be found around the $120 \mathrm{dbar}$ level at about $7.2^{\circ} \mathrm{C}$. Prominent in this figure are the often short-lived colder periods within this warm level between around 100 and $140 \mathrm{dbar}$. These can be present in one profile and absent in the next one, taken $4 \mathrm{~h}$ later. It is this dynamic change that makes it necessary to take repeated profiles over a longer time frame to establish the statistics of the fluctuations.

In Fig. 9 the dissolved oxygen concentration is plotted colour-coded over deployment time and pressure. All concentrations above $90 \mathrm{mmol} \mathrm{m}^{-3}$ are shown in red to spread the colour scale, emphasising the concentration changes in the hypoxic regions. When comparing the structures visible in the hypoxic regions with the structures seen in Fig. 7, it becomes clear that the colder intrusions are accompanied by higher dissolved oxygen concentrations. The most prominent feature is the patch of higher dissolved oxygen concentrations starting at around $120 \mathrm{~h}$ into the deployment (8 July 2010) and lasting for about $80 \mathrm{~h}$. Judging by the structure of the feature at a depth level of about $85 \mathrm{dbar}$, this event is certainly dominated by lateral movement through the profiling position. On 24 July 2010 a shorter-lived event reaches down some $20 \mathrm{dbar}$ into the anoxic zone.

\subsection{Third deployment}

The third deployment was carried out on 16 November 2010, and the system recorded 170 profiles from about $183 \mathrm{~m}$ depth to about $37 \mathrm{~m}$ depth, one profile every $8 \mathrm{~h}$. When recovery

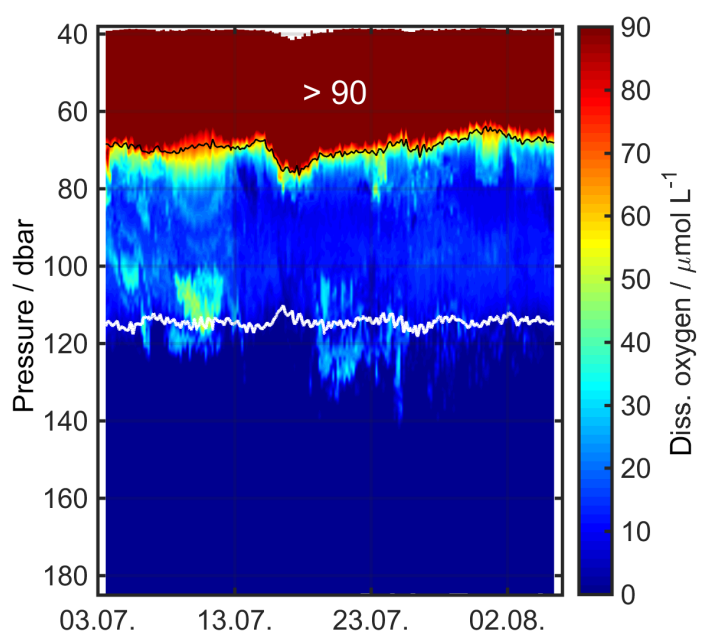

Figure 9. Plot of dissolved oxygen concentration (colour-coded) over deployment date and pressure. All concentrations above $90 \mu \mathrm{mol} \mathrm{m}^{-3}$ (the threshold between hypoxic and oxic waters) plotted in the same colour to emphasise dynamics in the hypoxic waters. The lines at around 70 dbar (black) and around $115 \mathrm{dbar}$ (white) denote the isopycnals of 1007.6 and $1009.5 \mathrm{~kg} \mathrm{~m}^{-3}$ respectively, indicating the division between oxic and hypoxic (upper line) and between hypoxic and anoxic waters (lower line).

took place on 7 February 2011, the PIP was found drifting on the sea surface. The winch had been programmed to take profiles until 11 February 2011 ( 270 profiles), in full awareness that this most likely would be above the battery capacity. The winch $\log$ files revealed that the winch was operating until 28 January 2011 (221 profiles), when the batteries were depleted. This number of profiles is in good agreement with the estimates based on the previous deployment and battery capacities.

When downloading the data from the CTD's memory, it showed that the CTD stopped recording profiles already on 11 January 2011, well before the anticipated end of battery capacity. Inspection of the battery voltage record shows two events where the battery voltage seems to suddenly decrease (see Fig. 10). At the same times the $\mathrm{pH}$ profiles showed a different shape than preceding or following ones. Inspection of the CTD at the manufacturers revealed the most likely cause of these events. On both occasions (and probably after the final profile recorded) the CTD did not disable power to the sensors during the almost $8 \mathrm{~h}$ between successive profiles; after the following profile, however, the CTD did switch off the sensors again. It can be assumed that the same happened again after the last recorded profile and during the $8 \mathrm{~h}$ the battery voltage dropped below the CTD's threshold of $9 \mathrm{~V}$ so that the CTD stopped recording after that time.

When looking at the different shape of the $\mathrm{pH}$ profiles immediately before and after the external sensors had been powered during the time between profiles (see Fig. 11), it becomes clear that the profile taken after the sensor was 


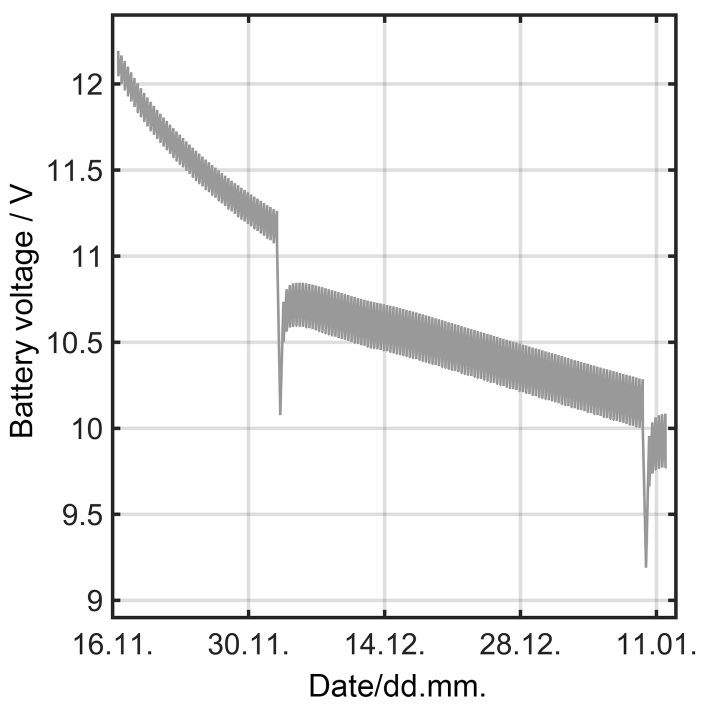

Figure 10. Battery voltage over the time of the third deployment from November 2010 to January 2011. The voltage usually drops during profiling and recovers during the $8 \mathrm{~h}$ sleep period. At 3 December and 9 January seemingly sudden drops in battery voltage occurred.

powered continuously for $8 \mathrm{~h}$ looks more reasonable; the measured $\mathrm{pH}$ remains constant in the anoxic water below ca. $125 \mathrm{dbar}$ as would be expected, and the slow decrease of $\mathrm{pH}$ in the earlier profile is assumed to be an artefact due to the storage of the $\mathrm{pH}$ electrode sensor in waters containing $\mathrm{H}_{2} \mathrm{~S}$ at concentrations around $80 \mu \mathrm{Ml}^{-1}$. While the $\mathrm{pH}$ electrode was specified as $\mathrm{H}_{2} \mathrm{~S}$-safe, the manufacturer had not anticipated the mode of operation employed for the profiling mooring; the $\mathrm{H}_{2} \mathrm{~S}$ resilience was stated for the more classical scenario of the powered $\mathrm{pH}$ electrode being introduced in the medium containing $\mathrm{H}_{2} \mathrm{~S}$ only for measurement and retrieved from the medium before powering off.

Assuming fairly constant parameters including $\mathrm{H}_{2} \mathrm{~S}$ at the parking depth, the same running-in characteristics can be expected after powering the $\mathrm{pH}$ electrode. Thus the $\mathrm{pH}$ profiles can be corrected by fitting a third-order polynomial to the difference between the two successive profiles and adding the resulting correction to the profiles taken after the power had been switched off between profiles. The interpretation of the corrected $\mathrm{pH}$ data, however, should be treated with great care. For future deployments the $\mathrm{pH}$ electrode will be powered continuously. As the $\mathrm{pH}$ electrode is a low-power sensor, this will decrease the potential recording time only by a negligible amount. The voltage drops experienced during the periods between profiles when the power did not switch off during this deployment were mainly due to the oxygen sensor, which has a power consumption of $0.6 \mathrm{~W}$.

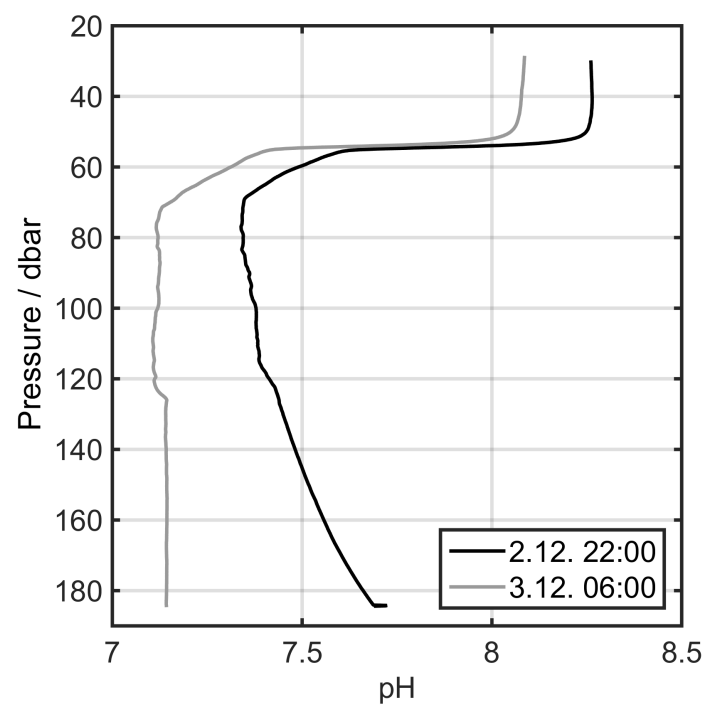

Figure 11. Two successive profiles of $\mathrm{pH}$, taken before the CTD failed to switch off power to the external sensors (2 December, 22:00 UTC, black) and $8 \mathrm{~h}$ later after sensors had been powered for 8 h (3 December, 06:00 UTC, grey).

\section{Conclusions and discussion}

The GODESS profiling mooring has been deployed successfully in the Gotland Deep of the Baltic Sea, taking 385 profiles over a deployment time of 89 days in total. The profiling mooring allowed for the first time the registration of the dynamics of oxygen and other redox-relevant parameters with high vertical and temporal resolution over an extended period of time in summer and winter situations. The datasets allow for detailed studies of the dynamics of the redoxcline and are a valuable resource for biogeochemical redoxcline investigations. Routinely employing the data from the profiling mooring will complement the ship-based sampling and analysis and provide an environmental context for ship campaigns.

In the first deployments the underwater winch and the PIP with its instrumentation worked reliably. The first deployments did, however, exhibit some handling problems on deployment and recovery that could jeopardise deployment success. Thus a re-design of the PIP will be carried out to improve handling of the system and also to incorporate additional sensors. A UV-visible absorption spectrometer will allow for high-resolution measurements of e.g. nitrate and $\mathrm{HS}^{-}$(Prien et al., 2009). Wet chemical analysers for Mn(II) and Fe(II) (Meyer et al., 2011; Prien et al., 2006) will also in future be added on some shorter deployments. A current meter is a further planned addition that will allow the direction of the origin of lateral intrusions to be determined.

The authors are aware that the application in the Gotland Basin brings with it a number of circumstances that make this comparatively simple system feasible. All data are only 
stored in the CTD in the PIP and would be lost should the tether break (e.g. caused by fishing activities or when, as happened in the third deployment, the PIP cannot be hauled in again when the winch batteries run out of energy). In these cases an independent satellite beacon could be added that would allow finding and collecting a drifting PIP in the enclosed environment of the Baltic Sea. The danger of fishing is certainly reduced in the deeper parts of the Gotland Basin that are hypoxic or anoxic during the stagnation periods between inflow events. With the experience of the first few deployments, especially the one where the batteries were completely depleted, deployments can be planned such that running out of battery power for the winch is made unlikely. The energy remaining in the batteries is routinely determined after each deployment.

As the interest lies on the redoxcline, the PIP does not need to go up to the surface, and thus the length of line installed on the winch can be reduced so that the PIP does not surface even with the winch running out of energy.

The winch manufacturer does offer the option to add an acoustic link to the winch, making it possible to control the winch from the PIP. An inductive link through a modified winch tether or during parking, when PIP and winch are in close proximity, could be added alternatively. In the latter case an optic link would be feasible as well. For GODESS we opted against this as it would have made addition of a control computer in the PIP necessary as well as modems on the PIP and winch, adding complexity and expense to the system.

The mooring position of the GODESS exhibits only weak currents of the order of $0.3 \mathrm{~m} \mathrm{~s}^{-1}$ so that the shape of the PIP can be kept relatively simple. An indicator for the effect of currents on the PIP is the shallowest depth reached in a profile as the winch always pays out the same length of tether. The maximum deviation between profiles has been about $3 \mathrm{~m}$ at a length of about $150 \mathrm{~m}$ of tether. For deployments in regions with higher currents, though, the outer shape of the PIP has to be streamlined to keep the power demand low for reeling the PIP back in.

With the described PIP and sensor suite the system has been proven as a useful tool for high temporal and vertical resolution investigations of the redoxcline in the Baltic Sea. It can assess small-scale dynamics in all weather conditions, i.e. also in situations when work from a ship is not possible. Taking profiles rather than measuring at multiple discrete depth levels has the advantage that recorded parameters can easily be referred to densities instead of pressure or depth (for an example see the animation of profiles in the Supplement to this paper). Profiling moorings like GODESS can also satisfy the requirements regarding temporal resolution that have been identified as necessary for a future Baltic monitoring system (Karlson et al., 2009).

The system is versatile as the PIP can be easily replaced by another one with a different sensor suite to target other science applications. The GODESS mooring is also a highly attractive test bed for new in situ sensors as the Gotland Basin redoxcline exhibits strong gradients in a number of potential target parameters as well as variations of parameters potentially causing cross-sensitivities.

\section{Data availability}

The datasets can be accessed via the following references: Prien, R. D.: Hydrochemistry measured at mooring station GODESS1. Leibniz Institute for Baltic Sea Research, Warnemünde, Unpublished dataset \#777607, https: //doi.pangaea.de/10.1594/PANGAEA.777607, 2012a.

Prien, R. D.: Hydrochemistry measured at mooring station GODESS2. Leibniz Institute for Baltic Sea Research, Warnemünde, Unpublished dataset \#777608, http: //doi.pangaea.de/10.1594/PANGAEA.777608, 2012b.

Prien, R. D.: Hydrochemistry measured at mooring station GODESS3. Leibniz Institute for Baltic Sea Research, Warnemünde, Unpublished dataset \#777609, http: //doi.pangaea.de/10.1594/PANGAEA.777609, 2012c.

\section{The Supplement related to this article is available online at doi:10.5194/os-12-899-2016-supplement.}

Acknowledgements. The GODESS mooring was one of the field observatories of the EU project HYPOX (EC grant 226213). The hardware was funded through the ZIP programme of the state of Mecklenburg-Vorpommern. The authors would like to thank Uwe Hehl for help with the mooring design and all aspects of deployment and recovery. Siggi Krüger was very helpful in many discussions on the system. The crews of the research vessels Albrecht Penck, Alkor, Heincke and Maria S. Merian we thank for excellent service and seamanship. We thank the reviewers for helpful comments and suggestions that led to an improved manuscript.

The publication of this article was funded by the open-access fund of the Leibniz Association.

Edited by: P. Chapman

\section{References}

Feistel, R., Nausch, G., Matthäus, W., and Hagen, E.: Temporal and spatial evolution of the Baltic deep water renewal in spring 2003, Oceanologia, 45, 623-642, 2003.

Jost, G., Clement, B., Pakhomova, S., and Yakushev, E.: Field studies of anoxic conditions in the Baltic Sea during the cruise of R/V Professor Albrecht Penck in July 2006, Oceanology, 47, 590593, doi:10.1134/S0001437007040170, 2007. 
Karlson, B., Axe, P., Funkquist, L., Kaitala, S., and Sorensen, K.: Infrastructure for marine monitoring and operational oceanography, Tech. Rep. 39, SMHI, Norrköping, http://www.smhi.se/ polopoly_fs/1.2071!/RO_39[1].pdf, 2009.

Meyer, D., Prien, R. D., Dellwig, O., Connelly, D. P., and Schulz-Bull, D. E.: In situ determination of iron(II) in the anoxic zone of the Central Baltic Sea using ferene as spectrophotometric reagent, Mar. Chem., 130-131, 21-27, doi:10.1016/j.marchem.2011.12.002, 2011.

Mohrholz, V., Naumann, M., Nausch, G., Krüger, S., and Gräwe, U.: Fresh oxygen for the Baltic Sea - An exceptional saline inflow after a decade of stagnation, J. Marine Syst., 148, 152-166, doi:10.1016/j.jmarsys.2015.03.005, 2015.

Nausch, G., Nehring, D., and Nagel, K.: Nutrient Concentrations, Trends and Their Relation to Eutrophication, 337-366, John Wiley \& Sons, Inc., doi:10.1002/9780470283134.ch12, 2008.

Prien, R., Meyer, D., and Sadkowiak, B.: Optical measurements of nitrate and $\mathrm{H}_{2} \mathrm{~S}$ concentrations in Baltic waters, Oceans $2009 \mathrm{Eu}-$ rope, 1-5, doi:10.1109/OCEANSE.2009.5278340, 2009.

Prien, R. D.: Hydrochemistry measured at mooring station GODESS1. Leibniz Institute for Baltic Sea Research, Warnemünde, Unpublished dataset \#777607, https://doi.pangaea.de/10.1594/PANGAEA.777607, 2012a.
Prien, R. D.: Hydrochemistry measured at mooring station GODESS2. Leibniz Institute for Baltic Sea Research, Warnemünde, Unpublished dataset \#777608, http://doi.pangaea.de/10.1594/PANGAEA.777608, 2012b.

Prien, R. D.: Hydrochemistry measured at mooring station GODESS3. Leibniz Institute for Baltic Sea Research, Warnemünde, Unpublished dataset \#777609, http://doi.pangaea.de/10.1594/PANGAEA.777609, 2012c.

Prien, R. D. and Schulz-Bull, D. E.: The Gotland Deep Environmental Sampling Station in the Baltic Sea, in: OCEANS 2011 IEEE - Spain, 1-5, IEEE, doi:10.1109/Oceans-Spain.2011.6003606, 2011.

Prien, R. D., Connelly, D. P., and German, C. R.: In Situ Chemical Analyser for the Determination of Dissolved Fe(II) and Mn(II), in: Ocean Sci. Meet., 87, OS44B-06, AGU, Honolulu, HI, USA, 2006. 